\title{
Surgeons Underestimate Their Patients' Desire for Preoperative Information
}

\author{
B. J. Keulers • M. R. M. Scheltinga • \\ S. Houterman · G. J. Van Der Wilt • \\ P. H. M. Spauwen
}

Published online: 12 April 2008

(C) The Author(s) 2008

\begin{abstract}
Background Provision of adequate patient information may contribute to a "satisfying" surgical treatment. The patient's views on successful transfer of information concerning operative characteristics may not be in concert with the surgeon's. The aim of the present study was to determine opinions of both surgeons and patients about issues of surgical information.

Methods A group of surgeons $(n=24)$ and surgical patients $(n=125)$ responded to a questionnaire that included 80 topics involving domains of information on disease, physical examination, preoperative period, anesthesia, operation, postoperative period, self care, and general hospital issues. Both groups were asked for their opinion on what they considered important and useful preoperative information for patients. Questions were scored with a visual analog scale. The reliability of the questionnaire was calculated with Cronbach's alpha.
\end{abstract}

Research institution: Department of Surgery. Máxima Medical Centre (MMC) Veldhoven, The Netherlands.

B. J. Keulers · M. R. M. Scheltinga $\cdot$ S. Houterman

Máxima Medical Centre (MMC), Veldhoven, The Netherlands

B. J. Keulers $(\square)$

Hatertseweg 491, Nijmegen 6533GJ, The Netherlands

e-mail: Bram_keulers@yahoo.com

G. J. Van Der Wilt

Department of Epidemiology and Biostatistics (Medical

Technology Assessment), University Medical Centre St

Radboud, Nijmegen, The Netherlands

P. H. M. Spauwen

Department of Plastic and Reconstructive Surgery, University

Medical Centre St Radboud, Nijmegen, The Netherlands
Differences in opinions between surgeons and patients were analyzed with Student's $t$-test.

Results The Cronbach's alpha of the questionnaire was high (0.91), indicating its high reliability. Patients scored significantly higher $(p<0.001)$ in most domains, including preoperative period, anaesthesia, operation, postoperative period, self care, and general hospital information. Women demonstrated a significantly higher need for information than men did. These findings were independent of patient age or complexity of operation. In contrast, surgeons thought that their patients desired more extensive information on cause, effect, and prognosis of the disease itself $(p<0.001)$.

Conclusion Surgeons generally underestimate their patients' desire for receiving extensive information prior to a surgical procedure of any complexity. Surgeons should develop strategies to bridge this informational mismatch.

\section{Introduction}

Medical specialists are highly committed to patient education and consider this an integral part of their profession [1]. These activities are time consuming, as doctors are thought to spend up to $25 \%$ of their office time providing information, instructing, and counseling. One may question whether these educational endeavors influence clinical management and patient outcome. However, successful exchange of medical information between a physician and a patient apparently contributes to improved outcome measured in terms of reduced treatment time and hospital stay [2-5]. Diminished medical needs, a higher level of physical and psychological well-being [6], improved risk behavior $[2,5,7]$, reduced risk factors [8-10], and less 
morbidity and mortality have also been reported to be associated with optimal exchange of information $[1,3,8-$ 11]. Well-informed patients are found to adopt a more active role in medical decision making and become more compliant with treatment objectives as their awareness and knowledge of treatment goals improve [1, 6, 12-17]. Eventually, higher levels of patient satisfaction are created that may even lead to lowered incidence of malpractice claims [18].

Hence, effective transfer of medical information is crucial in the provision of successful health care. These issues may be less clear when it comes to the surgical territory. A gap may be present between "what surgical patients want to know of their condition or treatment, and what their surgeons think they should know," as health care providers tend to underestimate patients' desire for information [12-16, 18-20]. However, there is little information on the quality and quantity of this "informational gap."

The purpose of this study was to identify the relative importance of various areas of information observed from two different angles, the surgical patient's perspective and the surgeon's perspective. We hypothesized that a substantial difference exists between what surgical patients considered important with respect to their condition and treatment as compared to the opinion of their surgeons.

\section{Methods}

The study was conducted in the Máxima Medical Centre (MMC), a teaching hospital serving approximately 350,000 inhabitants in the Eindhoven and Veldhoven region (The Netherlands) between December 2005 and May 2006. Initially, a literature study was conducted aimed at identifying information domains that have been found relevant to surgical patients before an operative procedure. The search strategy used standard sources (PubMed, literature lists of retrieved papers) and predefined key words (patient education, computer based, informed consent, decision making). Only studies that were published in the English language were selected. Topics that were considered important by the authors on subjective grounds were organized into eight domains including disease, examination, preoperative period, anesthesia, operation, postoperative period, self care, and general hospital information. For each domain, questions were composed resulting in an 80-item questionnaire. The answers to each of these 80 questions were quantified using a 100-mm visual analog scale (VAS). Each patient or surgeon was asked to put a mark along this $100-\mathrm{mm}$ scale ranging from "totally irrelevant to be informed on this item" (minimal score =0) via "neutral" (score $=50)$ toward "very relevant to be informed on this item" (maximal score $=100$ ). Characteristics including age, gender, and operative procedure were also tabulated. A first draft of this questionnaire was tested in random groups of patients-13 - and educational experts (psychologist-2, patient educator-1, doctors - 5) with the aim of improving its readability. It was also tested for face and content validity by the same educational experts. A revised second version of the questionnaire was used for the present study. Patients who were scheduled by their surgeon for a general surgical procedure were informed of the nature of the questionnaire and asked for their consent, after they had given consent for the surgery.

All patients were asked by personnel of the operative planning bureau to fill out the questionnaire and return it by mail. This was done on the day they visited the surgeon for consultation. They were allowed to address the questionnaire anonymously if they desired to do so. All staff surgeons and residents of the department of general surgery of the MMC were also asked to fill out the same questionnaire. The surgeons were asked for their opinion on what they thought patients generally desired to know on specifics of the operative procedure. Operations were classified from very easy (class 1) to complex (class 6) as proposed by a nationally accepted and utilized standard surgical complexity list.

\section{Statistical analysis}

Visual analog scale scores ranged from 0 to 100 and were registered in an Excel database. Results were analyzed with Student's $t$-test. Predefined subgroup analyses stratified for age ( $<50$ years versus $>50$ years) and complexity of operation (class 1-2 versus class 3-6) were performed. Reliability of the questionnaire was measured with Cronbach's alpha $(0=$ totally unreliable, $1=$ maximally reliable; a Cronbach alpha over 0.7 is acceptable). Cronbach's alpha increases when the correlations between the items of the questionnaire increase. Cronbach's alpha can take values between negative infinity and 1 . The higher the Cronbach's alpha, the better the internal consistency of the questionnaire. Data were expressed as mean \pm SD. A value of $p<0.05$ was considered statistically significant.

\section{Results}

The 80-item questionnaire was offered to 201 patients and 29 surgeons. Response rates were 62\% (125/201) and 83\% (24/ $29)$, respectively. The mean patient age was $54 \pm 15$ years, and mean surgeon age was $41 \pm 11$ years. Fifty-four percent of the patients were women. Simple (class 1-2) operations were performed in $68 \%$ of the cases, and $32 \%$ were class 3-6 procedures. These figures were based on 72 patients, as the 
Table 1 Desire for information on various domains judged by patients and surgeons

\begin{tabular}{lllrr}
\hline Domain & $\begin{array}{l}\text { Patients }^{\mathrm{a}} \\
(n=125)\end{array}$ & $\begin{array}{l}\text { Surgeons }^{\mathrm{a}} \\
(n=24)\end{array}$ & $\begin{array}{l}\text { Mean } \\
\text { difference } \\
(\mathrm{SD})\end{array}$ & $p$ Value \\
\hline 1. Disease & $78(17.0)$ & $81(7.8)$ & $-3.5(2.2)$ & 0.12 \\
2. Examination & $75(22.6)$ & $69(12.9)$ & $5.9(3.3)$ & 0.08 \\
3. Preoperative period & $72(15.1)$ & $60(11.2)$ & $11.7(3.2)$ & $<\mathbf{0 . 0 0 1}$ \\
4. Anesthesia & $81(15.0)$ & $67(15.3)$ & $13.8(3.4)$ & $<\mathbf{0 . 0 0 1}$ \\
5. Operation & $79(13.9)$ & $71(11.5)$ & $8.3(3.0)$ & $\mathbf{0 . 0 0 7}$ \\
6. Postoperative period & $76(15.6)$ & $58(14.0)$ & $18.1(3.4)$ & $<\mathbf{0 . 0 0 1}$ \\
7. Self care & $80(12.5)$ & $61(16.7)$ & $18.5(3.0)$ & $<\mathbf{0 . 0 0 1}$ \\
8. General information & $71(17.0)$ & $52(16.1)$ & $19.7(3.9)$ & $<\mathbf{0 . 0 0 1}$ \\
\hline
\end{tabular}

${ }^{a}$ Values are visual analog scale (VAS) scores; range: 0-100 with (SD) anesthesia, operation, postoperative period, self care, and general hospital information). Overall, the mean information relevance score among patients was $75 \pm 2$ ), and this score was $63( \pm 2)$ among surgeons $(p<0.01)$. In the patient group, women scored significantly higher on the information relevance score than men did (Fig. 1). In
Fig. 1 Desire for information on various domains judged by males and females



Domains

Domain

1. Disease

2. Examination

3. Pre-operative period

4. Anaesthesia

5. Operation

6. Post-operative period

7. Self care

8. General information

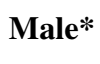

$(46 \%)$

77 (15.7)

71 (24.6)

$68(16.0)$

78 (15.6)

77 (12.1)

$73(15.8)$

$78(12.5)$

$69(15.1)$

Female*
$(50 \%)$

$(50 \%)$

78 (18.7)

78 (20.4)

76 (13.4)

83 (12.9)

82 (13.5)

79 (13.4)

82 (11.5)

73 (18.1)
Mean

difference

(SD)

$-0.89(3.2)$

$-7.60(4.2)$

$-8.3(2.8)$

$-5.4(2.7)$

$-5.3(2.4)$

$-6.3(2.8)$

-4.7 (2.2)

$-4.3(3.3)$ p-value

*Values are VAS-scores, range 0-100 with (SD) 
Table 2 Desire for information on general aspects of disease judged by patients and surgeons

\begin{tabular}{lllc}
\hline Disease & $\begin{array}{l}\text { Patients: mean } \\
\text { score }^{\mathrm{a}}\end{array}$ & $\begin{array}{l}\text { Surgeons: } \\
\text { mean score }\end{array}$ & $p$ Value \\
\hline Cause & $74(25.3)$ & $86(7.8)$ & $<\mathbf{0 . 0 0 1}$ \\
Effect & $83(18.6)$ & $88(6.9)$ & $\mathbf{0 . 0 1}$ \\
Symptoms & $79(22.6)$ & $79(17.3)$ & 0.90 \\
Change in symptoms & $82(21.5)$ & $84(10.0)$ & 0.46 \\
$\begin{array}{l}\text { Changed symptomatology } \\
\quad \text { after recurrence }\end{array}$ & $85(15.9)$ & $87(7.2)$ & 0.36 \\
Prognosis & $81(23.6)$ & $90(7.0)$ & $\mathbf{0 . 0 0 1}$ \\
Anatomy & $61(32.7)$ & $56(24.4)$ & 0.36 \\
\hline
\end{tabular}

${ }^{a}$ Values are VAS scores; range: $0-100$ with (SD)

contrast, age (age $<50$ years versus age $\geq 50$ years) and complexity of operation (class 1-2 versus class 3-6) did not differ in the patient group.

The overall Cronbach's alpha for this questionnaire was 0.91 (varying from 0.82 for domain preoperative period to 0.93 for domain examination). All domains are briefly discussed in the paragraphs that follow.

Information on disease (symptomatology, prognosis, etc)

The results show (Table 2) that surgeons thought that their patients desired more extensive information on cause, effect, and prognosis of the disease. The need for information on symptomatology associated with the disorder was judged important by both groups equally. Anatomical considerations related to the disorder were deemed less important by both patients and their surgeons.

\section{Information on preoperative examination/work-up}

Patients generally tended to judge information on specifics related to preoperative work-up more important compared to their surgeons $(p=0.08 \mathrm{~ns}$; Table 1). Methods of examination scored significantly higher in the patient group (74 \pm 24.7 versus $66 \pm 16.6 ; p=0.04$ ) (Table 3).

Preoperative period

There was a significant difference in scores on receiving details on the preoperative period in favor of the patients (72 \pm 15.1 versus $60 \pm 11.2 ; p<0.001)$ (Table 1$)$. Issues
Table 4 Desire for information on general aspects of preoperative period judged by patients and surgeons

\begin{tabular}{lllc}
\hline Preoperative period & $\begin{array}{l}\text { Patients: } \\
\text { mean score }\end{array}$ & $\begin{array}{l}\text { Surgeons: } \\
\text { mean score }\end{array}$ & $p$ Value \\
\hline Preoperative restrictions & $74(25.1)$ & $66(19.0)$ & 0.16 \\
Home preparation & $76(23.5)$ & $62(18.0)$ & $\mathbf{0 . 0 0 2}$ \\
Patient's own role & $78(23.0)$ & $75(12.2)$ & 0.34 \\
Preoperative restrictions & $86(14.4)$ & $80(10.5)$ & $\mathbf{0 . 0 4}$ \\
Preoperative medication & $79(24.0)$ & $78(10.8)$ & 0.78 \\
Medication at day of operation & $80(24.2)$ & $76(16.0)$ & 0.41 \\
Where to leave clothes /jewelry & $54(33.1)$ & $36(21.2)$ & $\mathbf{0 . 0 0 1}$ \\
Clothes during hospital stay & $55(33.2)$ & $31(20.6)$ & $<\mathbf{0 . 0 0 1}$ \\
Hospital policy & $63(28.7)$ & $48(21.0)$ & $\mathbf{0 . 0 0 4}$ \\
Hospital facilities & $61(24.0)$ & $47(21.6)$ & $\mathbf{0 . 0 1}$ \\
Last meal/drink & $82(16.9)$ & $64(23.9)$ & $\mathbf{0 . 0 0 1}$ \\
\hline
\end{tabular}

${ }^{a}$ Values are VAS scores; range: $0-100$ with (SD)

on home preparation, preoperative restrictions, lockers for clothes/jewelery, attire during hospital stay, hospital policy and facilities, and last meal/drink were judged significantly more important by patients than by surgeons (Table 4).

Anesthesia

Receiving details on anesthesia was deemed more important by patients $(81 \pm 15.0)$ compared to what their surgeons thought $(67 \pm 15.3 ; p<0.001$; Tables 1 and 5).

\section{Operation}

There was a significantly higher overall mean score in patients $(79 \pm 13.9$ versus $71 \pm 1.5 ; p<0.007$, Table 1$)$ concerning information on operation. Questions on specifics of procedure, operation time, location of operation room, waiting list, contact with family immediately postoperatively, and complication rate scored significantly higher in the patient group (Table 6).

\section{Postoperative period}

Patients demonstrated significantly higher overall mean scores than the surgeons on items related to the postoperative period $(76 \pm 15.6$ versus $58 \pm 14.0 ; p<0.001$; Table 1). Mean scores on questions concerning complaints, sensations, diet, personal hygiene, physical handicaps,
Table 3 Desire for information on general aspects of examination/work-up judged by patients and surgeons

a Values are VAS scores; range: $0-100$ with (SD)

\begin{tabular}{llll}
\hline Examination & Patients: mean score & & Surgeons; mean score \\
\hline Type of examination & $75(24.3)$ & $69(14.6)$ & $p$ Value \\
Reason for a examination & $75(24.1)$ & $72(16.3)$ & 0.18 \\
Method of examining & $74(24.7)$ & $66(16.6)$ & 0.41 \\
\hline
\end{tabular}


Table 5 Desire for information on general aspects of anaesthesia judged by patients and surgeons

\begin{tabular}{llll}
\hline Anesthesia & $\begin{array}{l}\text { Patients: } \\
\text { mean score }^{\mathrm{a}}\end{array}$ & $\begin{array}{l}\text { Surgeons: } \\
\text { mean score }^{\mathrm{a}}\end{array}$ & $p$ Value \\
\hline Type of anesthesia & $86(14.5)$ & $76(16.8)$ & $\mathbf{0 . 0 0 3}$ \\
Procedure & $79(21.3)$ & $72(18.7)$ & 0.10 \\
Anesthesia variations & $81(19.4)$ & $68(20.5)$ & $\mathbf{0 . 0 0 4}$ \\
Complications & $85(15.3)$ & $76(18.0)$ & $\mathbf{0 . 0 0 9}$ \\
Sensations during anesthesia & $78(25.7)$ & $60(25.5)$ & $\mathbf{0 . 0 0 2}$ \\
Awareness & $76(25.6)$ & $64(25.8)$ & $\mathbf{0 . 0 4}$ \\
Tension relief & $79(23.8)$ & $54(21.1)$ & $<\mathbf{0 . 0 0 1}$ \\
\hline
\end{tabular}

a Values are VAS-scores; range: $0-100$ with (SD)

Table 6 Desire for information on general aspects of operation judged by patients and surgeons

\begin{tabular}{lllc}
\hline Operation & $\begin{array}{l}\text { Patients: } \\
\text { mean score }^{\mathrm{a}}\end{array}$ & $\begin{array}{l}\text { Surgeons: } \\
\text { mean score }\end{array}$ & $p$ Value \\
\hline Various operations & $78(20.6)$ & $71(18.2)$ & 0.12 \\
Which operation & $86(13.1)$ & $85(9.8)$ & 0.83 \\
Why this operation & $80(20.3)$ & $82(15.1)$ & 0.60 \\
Experts opinion & $84(15.4)$ & $80(12.4)$ & 0.20 \\
Procedure & $82(19.3)$ & $66(23.0)$ & $\mathbf{0 . 0 0 4}$ \\
Operation time & $73(23.9)$ & $56(21.5)$ & $\mathbf{0 . 0 0 1}$ \\
Surgeon & $73(25.1)$ & $69(20.5)$ & 0.47 \\
Location OR & $72(26.6)$ & $57(26.7)$ & $\mathbf{0 . 0 1}$ \\
Preoperation consultation & $68(26.3)$ & $69(22.4)$ & 0.88 \\
Complications & $85(15.3)$ & $80(11.9)$ & 0.09 \\
Consequences/ complications & $86(15.3)$ & $80(12.1)$ & 0.08 \\
Complications chance & $82(20.4)$ & $68(18.1)$ & $\mathbf{0 . 0 0 2}$ \\
Notice family post OR & $77(23.7)$ & $65(22.0)$ & $\mathbf{0 . 0 2}$ \\
Waiting list & $81(19.6)$ & $64(22.1)$ & $<\mathbf{0 . 0 0 1}$ \\
\hline
\end{tabular}

${ }^{a}$ Values are VAS-scores; range: 0-100 with (SD)

home wound care, outpatient control, and permission to drive a vehicle were judged significantly more important by the patient group than by the surgeons (Table 7).

Self care

All answers to questions in the domain of self care indicated that patients considered these items more important than surgeons $(80 \pm 12.5$ versus $61 \pm 16.7 ; p<0.001)$ (Tables 1 and 8).

General hospital information

Answers to questions concerning the domain "general (hospital) information" indicated that the patient group deemed these items more important than the surgeons, with
Table 7 Desire for information on general aspects of postoperative period judged by patients and surgeons

\begin{tabular}{lllc}
\hline Postoperative period & $\begin{array}{l}\text { Patients: } \\
\text { mean score }\end{array}$ & $\begin{array}{l}\text { Surgeons: } \\
\text { mean score }\end{array}$ & $p$ Value \\
\hline Location post OR & $68(26.4)$ & $49(24.9)$ & $\mathbf{0 . 0 0 1}$ \\
Complaints after OR & $78(22.4)$ & $62(16.9)$ & $\mathbf{0 . 0 0 1}$ \\
Sensations after OR & $71(25.7)$ & $54(21.5)$ & $\mathbf{0 . 0 0 3}$ \\
Diet & $79(23.4)$ & $50(20.9)$ & $<\mathbf{0 . 0 0 1}$ \\
Personal hygiene & $75(24.3)$ & $43(21.6)$ & $<\mathbf{0 . 0 0 1}$ \\
Physical handicaps & $84(17.9)$ & $67(17.7)$ & $<\mathbf{0 . 0 0 1}$ \\
Home wound care & $87(15.3)$ & $68(19.7)$ & $<\mathbf{0 . 0 0 1}$ \\
Allowed to drive & $72(31.9)$ & $58(25.5)$ & $\mathbf{0 . 0 5}$ \\
Outpatient department control & $84(19.2)$ & $60(20.7)$ & $<\mathbf{0 . 0 0 1}$ \\
Location outpatient department & $74(22.5)$ & $51(22.2)$ & $<\mathbf{0 . 0 0 1}$ \\
Resume work & $65(30.3)$ & $66(18.9)$ & 0.93 \\
Total rehabilitation & $72(26.0)$ & $63(21.4)$ & 0.16 \\
\hline
\end{tabular}

${ }^{a}$ Values are VAS scores; range: 0-100 with (SD)

Table 8 Desire for information on general aspects of self care judged by patients and surgeons

\begin{tabular}{lllc}
\hline Self care & $\begin{array}{l}\text { Patients: } \\
\text { mean score }^{\mathrm{a}}\end{array}$ & $\begin{array}{l}\text { Surgeons: } \\
\text { mean score }^{\mathrm{a}}\end{array}$ & $p$ Value \\
\hline When to contact & $81(18.0)$ & $72(19.6)$ & $\mathbf{0 . 0 3}$ \\
Wound healing & $78(21.4)$ & $56(20.0)$ & $<\mathbf{0 . 0 0 1}$ \\
Self care complaints & $83(16.3)$ & $61(21.7)$ & $<\mathbf{0 . 0 0 1}$ \\
Contribution rehabilitation & $86(13.5)$ & $66(22.5)$ & $<\mathbf{0 . 0 0 1}$ \\
Relieve pain and discomfort & $85(16.3)$ & $60(23.3)$ & $<\mathbf{0 . 0 0 1}$ \\
Activity restrictions & $88(13.1)$ & $62(23.3)$ & $<\mathbf{0 . 0 0 1}$ \\
Rehabilitation program & $79(23.4)$ & $64(21.5)$ & $<\mathbf{0 . 0 0 1}$ \\
Home care management & $79(23.9)$ & $64(20.4)$ & $\mathbf{0 . 0 0 6}$ \\
Cessation treatment & $83(19.3)$ & $68(19.6)$ & $\mathbf{0 . 0 0 3}$ \\
Addresses patient support ea. & $55(28.7)$ & $41(23.6)$ & $\mathbf{0 . 0 3}$ \\
\hline
\end{tabular}

${ }^{a}$ Values are VAS scores; range: 0-100 with (SD)

the exception of a question on internet pages for patient support groups (Table 9).

\section{Discussion}

The present study confirms the supposition that surgical patients, even in a "semi-rural" environment, are interested in all domains of the hospital admission process. In the present study striking differences in opinions were observed in the domains of postoperative period and self care, as patients judged these issues approximately $25 \%$ more important compared to their surgeons. On the other hand, our surgeons are convinced that their patients are predominantly focused on aspects belonging to domains of disease, examination, and operation. 
Table 9 Desire for information on general aspects judged by patients and surgeons

\begin{tabular}{lllc}
\hline General & $\begin{array}{l}\text { Patients: } \\
\text { mean score }^{\mathrm{a}}\end{array}$ & $\begin{array}{l}\text { Surgeons: } \\
\text { mean score }^{\mathrm{a}}\end{array}$ & $p$ Value \\
\hline Emergency & $79(20.4)$ & $68(19.8)$ & $\mathbf{0 . 0 2}$ \\
Medications & $74(23.5)$ & $56(21.8)$ & $\mathbf{0 . 0 0 1}$ \\
Side effects & $77(23.5)$ & $53(21.0)$ & $<\mathbf{0 . 0 0 1}$ \\
Adjust current medications & $74(26.39)$ & $58(20.52)$ & $\mathbf{0 . 0 0 8}$ \\
General hospital policy & $61(26.0)$ & $42(22.9)$ & $\mathbf{0 . 0 0 2}$ \\
Personnel staff function & $63(28.3)$ & $40(21.9)$ & $<\mathbf{0 . 0 0 1}$ \\
Personnel responsibilities & $64(29.1)$ & $49(28.3)$ & $\mathbf{0 . 0 2}$ \\
Who to turn to & $79(21.9)$ & $58(20.6)$ & $<\mathbf{0 . 0 0 1}$ \\
Internet pages & $56(31.6)$ & $47(28.0)$ & 0.22 \\
Telephone numbers & $71(24.7)$ & $57(18.3)$ & $\mathbf{0 . 0 0 4}$ \\
Informed consent & $69(27.0)$ & $47(30.6)$ & $<\mathbf{0 . 0 0 1}$ \\
Right to information & $70(26.8)$ & $45(26.3)$ & $<\mathbf{0 . 0 0 1}$ \\
Complaints/claims & $67(27.2)$ & $38(26.2)$ & $<\mathbf{0 . 0 0 1}$ \\
Medical record & $76(22.8)$ & $46(29.6)$ & $<\mathbf{0 . 0 0 1}$ \\
Finances & $74(25.8)$ & $58(26.5)$ & $\mathbf{0 . 0 0 6}$ \\
Information plan changes & $86(16.3)$ & $68(25.0)$ & $\mathbf{0 . 0 0 2}$ \\
\hline Vales &
\end{tabular}

${ }^{\text {a }}$ Values are VAS scores; range: 0-100 with (SD)

The results of this study show that surgeons underestimated their patients' need for extensive and adequate provision of preoperative information. Surgeons routinely fail to meet their clients' hunger for information and apparently misperceive the process of information transfer $[6,12-17]$. One study concluded that doctors underestimate their patients' desire for information in $65 \%$ of their encounters [18]. Surgical patients in an interviewed group of 60 patients were also found to have a selective informational desire as they appeared more interested in specifics of the operation and recovery ( $43.3 \%$ each) than in operative risks $(33.3 \%)$ [21]. Another study including patients receiving hip surgery demonstrated that they were eager to know almost all aspects of their operation, in contrast to what their doctors thought [22].

Different patient characteristics determine this desire for preoperative information. Gender apparently plays a role, as women visit doctors more often, require more emotional support, ask more questions, and are engaged in more verbal behavior with health care providers compared to men $[18,13]$. This higher need for information associated with female gender is anticipated by their doctors, as women usually receive more doctor time and more levels of explanations [18]. The present study confirms this gender difference, as women surgical patients scored significantly higher than their male counterparts in all domains except issues related to the domains disease, examination, and general information (all of which were scored higher by women, but not significantly). Informational needs were not related to the patient's age.
One would assume that complex surgery a priori requires more explanation, and patients scheduled to undergo class 3-6 operations would demand more information than patients undergoing simple class 1-2 surgery, because the topic is more complex and complications more severe. However, our results do not confirm this assumption. In contrast, patients that were scheduled to undergo a class 1-2 operation scored higher in the "self-care" domain than the class 3-6 patients. This apparent contradiction may be explained by the fact that class $1-2$ patients are quickly discharged (most of the time on the day of operation) and immediately have to rely on themselves to cope with daily demands. Interpretation of these results must be performed with caution, however, as our patients were allowed to answer questions regarding the operative procedure anonymously, and only 58\% of the patients $(n=72)$ reported their operative procedure on the questionnaire. We have no indications that patients who are scheduled for more complex operations have greater informational needs as compared to patients who are scheduled for simpler operative procedures.

Current care providers intend to use the most effective ways to adequately deliver sets of required information that patients can reproduce at any time. Unfortunately, patients appear to remember only few items of all the information that is transferred by their doctors. Their level of knowledge quickly deteriorates from the initial consultation on, despite supportive measures, including information booklets. It may even be argued that patients are insufficiently informed to properly consent to a standard "informed consent procedure" $[24,25]$. Improving patient information using alternative strategies may have an impact on these issues and may also have legal consequences.

How can results of the present study be transferred to daily surgical practice? Time restraints as well as lack of skills in basic communication are common in a surgical practice and contribute to suboptimal transfer of information. It is clear from this and other studies that major improvements have to be made in patient education. Interactive computer programs may contribute to solving these problems. One study evaluating the efficacy of a video film on inguinal hernia repair demonstrated improved patient understanding, higher satisfaction, and reduced doctors' time [24]. Moreover, interactive computer programs appear capable of drastically improving knowledge retention from $20 \%$ to $80 \%$ and may thus be a great improvement for informed consent procedures [26]. A computer program does have the time to discuss all important domains to any extent a patient chooses without ever forgetting important information [27]. A computer program has the potential of aiding in educating patients on specific issues related to the scheduled operative procedure and it buys time for surgeons to answer specific questions. 
A recent trial comparing patient education by a doctor or a computer program concluded that doctors indeed can be replaced by a computer program [28]. Patients learned more by using the computer program and were also equally satisfied with either education they received. Modern surgical practice can be improved by using interactive computer programs in patient education.

One may question whether the design of the present study is optimal. For instance, conclusions were drawn on the basis of comparisons of VAS scores. A recent study concluded that an alternative verbal rating score (VRS) may perform better compared to a VAS system [29]. Irrespective of the design, the present study demonstrates that improvements in patient education in general are needed and probably attainable. Future research on the efficacy of computer techniques as an alternative for patient education is warranted.

Acknowledgment This study was supported by the Stichting Hart-en Vaatzieken Zuid-Oost Nederland.

Open Access This article is distributed under the terms of the Creative Commons Attribution Noncommercial License which permits any noncommercial use, distribution, and reproduction in any medium, provided the original author(s) and source are credited.

\section{References}

1. Grueninger UJ, Goldstein MG, Duffy FD (1990) A conceptual framework for interactive patient education in practice and clinic settings. J Hum Hypertens 4(Suppl 1):21-31

2. Pederson LL (1982) Compliance with physician advice to quit smoking: a review of the literature. Prev Med 11:71-84

3. Mullen PD, Mains DA, Velez R (1992) A meta-analysis of controlled trials of cardiac patient education. Patient Educ Couns 19:143-162

4. Krishna S (1997) Clinical trials of interactive computerized patient education: implications for family practice. Fam Pract 45:25-33

5. Mullen PD, Green LD, Persinger GS (1985) Clinical trials of patient education for chronic conditions: a comparative metaanalysis of intervention types. Prev Med 14:753-781

6. Breemhaar B, Van den Borne HW (1991) Effects of education and support for surgical patients: the role of perceived control. Patient Educ Couns 18:199-210

7. Rosen MA, Logsdon DN (1985) The insure project on preventive health services. Stat Bull Metrop Ins Co 66:25-27

8. Holme I, Hjermann I, Helgeland A et al (1985) The Oslo Study: diet and antismoking advice. Additional results from a 5-year primary preventive trial in middle-aged men. Prev Med 14:279292
9. Levine DM, Green LW, Deeds SG et al (1979) Health education for hypertensive patients. JAMA 241:1700-1703

10. Stamler J, Farinaro E, Mojonnier LM et al (1980) Prevention and control of hypertension by nutritional-hygienic means. Long-term experience of the Chicago Coronary Prevention Evaluation Program. JAMA 243:1819-1823

11. Morisky DE, Levine DM, Green LW et al (1983) Five-year blood pressure control and mortality following health education for hypertensive patients. Am J Public Health 73:153-162

12. Brody DS, Miller SM, Lerman CE et al (1989) Patient perception of involvement in medical care: relationship to illness attitudes and outcomes. J Gen Intern Med 4:506-511

13. Brody DS (1980) The patient's role in clinical decision-making. Ann Intern Med 93:718-722

14. Cassileth BR, Zupkis RV, Sutton-Smith K et al (1980) Information and participation preferences among cancer patients. Ann Intern Med 92:832-836

15. Ende J, Kazis L, Ash A et al (1989) Measuring patients' desire for autonomy: decision making and information-seeking preferences among medical patients. J Gen Intern Med 4:23-30

16. McIntosh J (1974) Processes of communication, information seeking and control associated with cancer: a selective review of the literature. Soc Sci Med 8:167-187

17. Temple WJ, Temple WJ, Russell ML et al (2006) Conservation surgery for breast cancer as the preferred choice: a prospective analysis. J Clin Oncol 24:3367-3373

18. Waitzkin H (1984) Doctor-patient communication. Clinical implications of social scientific research. JAMA 252:2441-2446

19. Breemhaar B (1992) Voorlichting aan operatiepatiënten: knelpunten. Med Contact 47:684-686

20. Seeman M, Evans J (1962) Alienation and learning in a hospital setting. Sociol Rev 27:772-782

21. Hoermann S, Doering S, Richter R et al (2001) Patients' need for information before surgery. Psychother Psychosom Med Psychol 51:56-61

22. Doust JA, Morgan TN, Weller BJ et al (1989) Patient desire for information before a total hip-replacement operation. Med J Aust 151:201-203

23. Tabenkin H, Goodwin MA, Zyzanski SJ (2004) Gender differences in time spent during direct observation of doctor-patient encounters. J Womens Health (Larchmt) 13:341-349

24. Kriwanek S, Armbruster C, Beckerhinn P et al (1998) Patients' assessment and recall of surgical information after laparoscopic cholecystectomy. Dig Surg 15:669-673

25. Turner P, Williams C (2002) Informed consent: patients listen and read, but what information do they retain? $\mathrm{N} \mathrm{Z}$ Med $\mathrm{J}$ 115:U218

26. Begley S (1994) Teaching minds to fly with discs and mice. Newsweek May 31, p 47

27. Keulers BJ, Spauwen PHM (2003) Can face-to-face patient education be replaced by computer-based patient education? Eur J Plastic Surg 26:280-284

28. Keulers BJ, Welters CFM, Spauwen PHM et al (2007) Can faceto-face education be replaced by computer-based patient education? A randomised trial. Patient Educ Couns 67:176-182

29. Loos MJ, Houterman S, Scheltinga MR et al (2007) Evaluating postherniorrhaphy groin pain: Visual Analogue or Verbal Rating Scale? Hernia 15 [Epub ahead of print] 